\title{
Effects of Mock Facebook Workday Comments on Public Perception of Professional Credibility: A Field Study in Canada
}

Cynthia Weijs ${ }^{1,2}$, MPH, PhD; Jason $\mathrm{Coe}^{2}$, DVM, PhD; Serge Desmarais ${ }^{3}, \mathrm{PhD}$; Shannon Majowicz ${ }^{4}$, PhD; Andria Jones-Bitton ${ }^{2}$, DVM, PhD

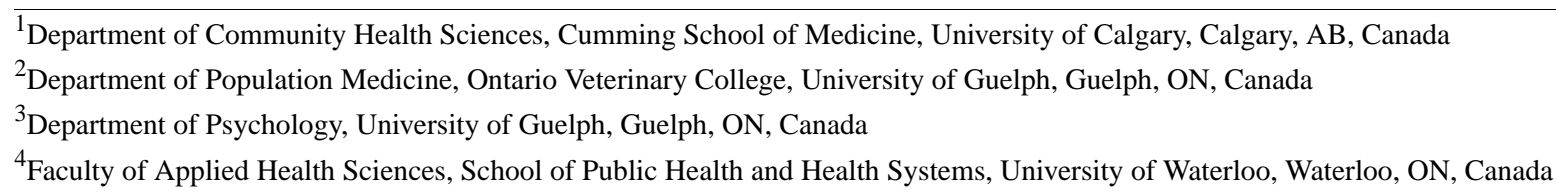

Corresponding Author:

Cynthia Weijs, MPH, PhD

Department of Community Health Sciences

Cumming School of Medicine

University of Calgary

TRW3, 3280 Hospital Dr. NW

Calgary, AB, T2N 4Z6

Canada

Phone: 14032204299

Email: cynthia.weijs@ucalgary.ca

\section{Abstract}

Background: There is considerable discussion of risks to health professionals' reputations and employment from personal social media use, though its impacts on professional credibility and the health professional-client relationship are unknown.

Objective: The aim of this study was to test the extent to which workday comments posted to health professionals' personal Facebook profiles influence their credibility and affect the professional-client relationship.

Methods: In a controlled field study, participants (members of the public) reviewed randomly assigned mock Facebook profiles of health professionals. The $2 \times 2 \times 2$ factorial design of mock profiles included gender (female/male), health profession (physician/veterinarian), and workday comment type (evident frustration/ambiguous). Participants then rated the profile owner's credibility on a visual analog scale. An analysis of variance test compared ratings. Mediation analyses tested the importance of credibility ratings on participants' willingness to become a client of the mock health professional.

Results: Participants (N=357) rated health professionals whose personal Facebook profile showed a comment with evident frustration rather than an ambiguous workday comment as less credible $(P<.001$; mean difference 11.18 [SE 1.28]; $95 \%$ CI 8.66 to 13.70). Furthermore, participants indicated they were less likely to become clients of the former when they considered credibility (standardized beta $=.69 ; P<.001$ ). Credibility explained $86 \%$ of the variation in the relationship between the type of workday comment and the participant's willingness to become a client of the health professional.

Conclusions: This study provides the first evidence of the impact of health professionals' personal online disclosures on credibility and the health relationship. Public perceptions about professionalism and credibility are integral to developing the evidence base for e-professionalism guidelines and encouraging best practices in social media use.

(J Med Internet Res 2019;21(4):e12024) doi: 10.2196/12024

\section{KEYWORDS}

social media; professionalism; trust; professional-patient relations; medical education 


\section{Introduction}

\section{Changing Context of Professionalism}

Professionalism is important to the health professional-client relationship (hereafter, the health relationship) [1]. Perceptions of professional credibility, generally defined as caring, competence, and trustworthiness [2], underpin clients' sense of professionalism [1,3]. Typically, such impressions are formed during health interactions, though widespread internet use has introduced new contexts for impression formation. In one survey, $80 \%$ of US internet users sought health information online, with $44 \%$ specifically searching for information about health professionals [4]. Social media have garnered attention as being a risk to health professionals who use such sites in their personal lives. One site, Facebook, may reveal significant personal information that health professionals would be unlikely to share in the course of a client interaction. Given Facebook's immense popularity with the public $[5,6]$ and health professionals [7-11], and the call for evidence about public impressions of credibility developed in this new context [12], we explored public impressions of health professionals who use Facebook in their private lives.

\section{Reputation Risk When Private and Professional Lives Mix Online}

An important issue is the need to strike a balance between health professionals' right to use Facebook as private citizens and their duty to protect professional reputation and health relationships $[13,14]$. Reputation damage, as evidenced by employment loss and regulatory discipline $[15,16]$, has occurred. However, the consequence to the health relationship from health professionals' personal use of Facebook, or whether patients notice these behaviors or see them as inappropriate, is complex and less evidenced. Yet, 49 out of 72 (68\%) of medical students surveyed in a social media and professionalism intervention reported the mixing of their personal and professional lives on social media sites as a key concern [17].

Normative beliefs about online or e-professionalism among some practicing health professionals and trainees differ considerably $[7-9,11,18]$, perhaps mirroring the professionalism transition seen in the academic and medical education literature, from the old (unquestioned authority, paternalistic, and emotionally distant) to the new (client-centered, collaborative, and emotionally present) [19]. Some see e-professionalism as a matter of taste, overly rigid, individual, and impossible to attain [10]. Although it has been a decade since the advent of social media, very little evidence exists to inform social media guidelines about the interplay between personal online disclosures and professional trust and credibility [12] or whether expectations of e-professionalism might differ between health professional groups.

\section{Objectives}

We explored the impact of workday comments that blur the line between health professionals' private and professional lives as they are common and thought to have an impact on perceived professionalism [18,20-22]. We aimed to test (1) whether members of the public independently notice workday comments on Facebook profiles belonging to physicians or veterinarians, (2) whether such comments influence perceptions of professionalism (operationalized as credibility evaluations), and (3) the impact on the willingness of participants to engage with those health professionals (ie, become a client).

\section{Methods}

\section{Informed Consent and Recruitment}

The study was approved by the Research Ethics Board at the University of Guelph. Informed consent consisted of a welcome message and a letter of information on the landing page of a Web-based questionnaire. The sample was a convenience sample. Participants were recruited in person in communities across Southwestern Ontario or online, through local social media (ie, advertisements about the study on Facebook and Kijiji, a popular online classifieds site in Canada). Members of the public were approached in public spaces (eg, farmers' markets, public trailheads, parks, soccer fields, and sports games) to take part in a study described as aiming to understand people's first impressions of personality from online content. Participants who showed interest in participating were given a card with the researchers' contact information and URL for the survey. The survey was open and voluntary. To control potential social desirability bias, no mention was made of health professionals [23]. Participants were encouraged to share the online survey link through email and Facebook. Data were captured automatically by a Web survey application, Fluidsurvey, and downloaded onto password protected and encrypted computers. After completing the survey, participants submitted their email contact information on a separate webpage to have a 1 in 350 chance of winning an Apple iPad.

\section{Survey Design}

The first of 3 survey sections presented a randomly assigned mock Facebook profile in PDF format for participants' review (a mock profile is available to readers from the authors upon request). The second survey section presented an adapted credibility scale on which participants rated the mock profile owner [2]. Finally, 16 demographic questions and 1 question asking participants about their willingness to become a client of the profile owner (a physician or veterinarian) were presented. 
Table 1. Adapted credibility scale showing paired anchor characteristics for competence, caring, and trustworthiness (Cronbach alpha for the scale $=.88$ ). Two changes were made to the original validated scale ${ }^{a, b}$.

\begin{tabular}{lll}
\hline Competence & Caring & Trustworthiness \\
\hline Novice/Expert & Insensitive/Sensitive & Phoney/Genuine \\
Unintelligent/Intelligent & Not understanding/Understanding & Unethical/Ethical \\
Incompetent/Competent & Self-centered/Unselfish & Untrustworthy/Trustworthy \\
Uninformed/Informed & Unconcerned/Concerned & Dishonest/Honest \\
Dim/Bright & Uncaring/Caring & Immoral/Moral \\
Untrained/Trained & Doesn't care about me/Cares about me ${ }^{\mathrm{b}}$ & Dishonourable/Honourable \\
\hline
\end{tabular}

${ }^{\text {a }}$ Dim replaced the original adjective, Stupid.

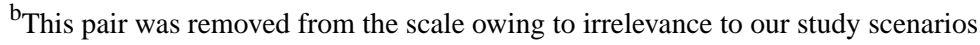

Profiles were made to simulate a real Facebook profile, although without working links and with names and headshot photos contributed by members of the research team with permission. Profiles were created using a $2 \times 2 \times 2$ full factorial design, with the following attributes: mock profile owner gender (female/male), health discipline (physician/veterinarian), and workday comment type (evident frustration/ambiguous). Profile comments (ie, status updates) were modeled after actual status updates from previous studies of health professionals' personal use of Facebook to authentically portray workday comments as they may be encountered online [18,20-22]. Profile photos of Sarah or Chad, the mock profile owners, were of a sunset, to control for potential bias related to facial features upon first impression. Several workday comments were pilot tested within the research team and with members of the public for content validity. In our post pilot test debrief, we asked participants what they understood the paired adjectives to mean. They all identified at least one of the exact labels of the scale (competence, caring, trustworthiness, or credibility) or a synonym of the scale (eg, professionalism). Additionally, we inquired about their views on the piloted comments as we aimed for a moderate comment in terms of emotional valence. On the basis of their feedback, we chose the following evident workday frustration comment:

What is it with some people?? I know I only went through 9 years of university...but really, I know what I'm talking about...yeesh!!! [Sarah or Chad]

We also chose the following ambiguous workday comment:

Started with new electronic patient charts today...interesting experience for sure. [Sarah or Chad]

Each participant reviewed the content of 1 randomly assigned mock Facebook profile without time constraints. On the next page, they completed the 17 personality ratings, an adapted credibility scale which included 3 subscales: competence (6 items), caring (5 items), and trustworthiness ( 6 items; Table 1$)$ [2]. The scale originates from a widely cited study by McCroskey and Teven that validated a credibility scale composed of 3 related dimensions-goodwill (caring), competence, and trustworthiness [2]. We modified 2 items in the scale, replacing the original adjective, stupid, with dim in the competence subscale and removing 1 set of adjectives that was not relevant to our scenarios in the goodwill or caring subscale (Table 1).

Each item was represented on a visual analog scale, anchored at each end with an adjective describing less (eg, novice) or more (eg, expert) of the trait being assessed (eg, competence). Consistent with first impression research, participants were asked to move fairly quickly through all randomly presented rating scales, sliding the cursor to the place on the line between the 2 adjectives that they felt best represented the profile owner [24,25]. The question assessing a participant's willingness to become a client of the mock profile owner was similarly represented, anchored by very unlikely and very likely.

Numeric gradations for all visual analog scales (0 to 100) were hidden to access participants' immediate impressions. Only one response was possible, and all items had a nonresponse option of nonmovement from the middle position on the scale (neutral). Respondents were able to review and change their answers before moving to the next page and could not move backward in the survey so as to ensure collection of their first impressions. Duplicate entries were identified through a combination of internet protocol address and demographic details. All submitted surveys were included in the analysis, except those that were less than half complete or had fewer than 2 credibility subscales completed. The survey was pretested on a group of 10 individuals known to the researchers who were debriefed upon completing the survey about usability, clarity, functionality, and content validity of the credibility scale.

\section{Statistical Analysis}

Univariable linear regression identified unconditional associations between the outcome variable (credibility rating) and covariate or control variables including the following: participant is a Facebook profile owner (no; yes); recruitment (in person; online); participant age (years); participant gender (female; male); annual household income before taxes (low $\leq$ Can $\$ 74,999$; high $\geq$ Can $\$ 75,000$ ); and participant's profile viewing and rating times (in seconds). Covariates having a $P$ value <.20 with the outcome variable were included in an omnibus analysis of variance (ANOVA), along with the 3 manipulated mock profile factors (profile owner gender, health discipline, and workday comment type), to determine credibility differences based on comment type. 
Sequential linear regression determined the extent to which impressions gleaned from the online content of a personal Facebook profile impact the health relationship [26]. Specifically, credibility was assessed for its role as a mediator (intervening variable) in the relationship between profile workday comment type and the participant's willingness to become a client of the profile owner. As above, univariable linear regression was employed to reduce variables eligible for inclusion in the model. In Step 1, the 3 manipulated variables in our study and any eligible covariates were entered into the model. In Step 2, credibility was added to the model. Mediation was supported if the intervening variable maintained a significant standardized beta coefficient when all other covariates were controlled [26]. Full mediation as per Tabachnick and Fidell was considered to have occurred when beta coefficients for significant variables in Step 1 were no longer significant in Step 2 [26]. Effect size, as per Cohen, and 95\% CIs for the sequential regression model were calculated $[27,28]$. All statistical analyses were carried out in SPSS v23 (SPSS, Inc) using a significance level of $P<.05$.

\section{Results}

\section{User Statistics}

The total number of people invited to participate in the survey is unknown. A total of 6 surveys were removed owing to insufficient responses, leaving 357 usable surveys. Not all participants answered all questions, thus samples vary as noted below. A missing value analysis revealed that values were missing completely at random [26]. Participants were, on average, 40 years old (median 40 (SD 12.4); range 18-73) and 226 out of $355(63.7 \%)$ were female. Participants' income and education are shown in Table 2. Most participants (289/348, $83.0 \%$ ) reported having a personal Facebook profile, and among those, 159 out of $285(55.8 \%)$ reported checking it daily or several days per week $(57 / 285,20.0 \%)$. On average, participants viewed the mock Facebook profiles for 87 seconds (median 74 (SD 62); range 6.23-592 seconds), took 124.00 seconds (median
110 (SD 61.5); range 32-652 seconds) to rate the mock profile owners, and took 7.15 min (median 6.60 (SD 2.54); range 2.18-17.53 $\mathrm{min}$ ) to complete the entire survey.

\section{Differences in Credibility Ratings of Health Professionals Having Either Evident Frustration or Ambiguous Comments on Mock Facebook Profiles}

The following variables were included in the omnibus ANOVA: workday comment type, mock profile owner discipline and gender, participant age and gender, participant profile viewing time, and recruitment venue (in person, online). The ANOVA results yielded only one statistically significant main effect-workday comment type, $F_{1,339}=64.03 ; P<.001$ - that is, mock Facebook profile owners with an evident workday frustration comment were rated as significantly less credible than were those with an ambiguous workday comment (mean difference 11.2 (SE 1.3); 95\% CI 8.66 to 13.70). The average credibility rating for evident profiles was 56.7 out of 100 , whereas for ambiguous profiles it was 67.9 out of 100 . The model-adjusted $\mathrm{R}^{2}$ was 0.188 , indicating $19 \%$ of the variation in credibility ratings was due to the workday comment type.

\section{Understanding the Real-World Effect of Workday Comments and Credibility Ratings on Health Relationships}

Sequential regression supported mediation, meaning that the effect of workday comment type (evident frustration versus ambiguous) on participants' willingness to become a client of health professional profile owners was mediated by credibility ratings (Tables 3 and 4 ). Cohen $\mathrm{f}^{2}$ effect size for the model was large $\left(0.86 ; 95 \% \mathrm{CI}\right.$ for $\mathrm{f}^{2} 0.62$ to 1.18$)$, meaning $86 \%$ of the variation in participants' willingness to become a client of mock health professional profile owners was due to the addition of credibility rating to the model. Participants perceived the profile comment as a reflection of credibility, which subsequently impacted their willingness to become a client of the profile owner (higher credibility ratings associated with more willingness).

Table 2. Number (n) and proportion (\%) of study participants within pretax annual household income and completed education categories.

\begin{tabular}{|c|c|}
\hline Demographic characteristic & $\mathrm{n}(\%)$ \\
\hline Pretax annual household income in Can \$ & $\mathbf{n}=\mathbf{3 3 5}$ \\
\hline$<\$ 30,000$ & $50(15)$ \\
\hline$\$ 30,000-\$ 49,999$ & $42(13)$ \\
\hline$\$ 50,000-\$ 74,999$ & $75(22)$ \\
\hline$\$ 75,000-\$ 99,999$ & $71(21)$ \\
\hline$\geq \$ 100,000$ & $97(29)$ \\
\hline Level of completed education & $\mathbf{n}=\mathbf{3 5 7}$ \\
\hline Completed or have some high school & $52(14)$ \\
\hline College diploma & $66(18)$ \\
\hline University degree & $118(33)$ \\
\hline Professional degree & $48(13)$ \\
\hline Graduate degree & $72(22)$ \\
\hline
\end{tabular}


Table 3. Step 1 of the sequential regression examining credibility as a mediator in the relationship between workday comment type and willingness to become a patient of the health professional for 318 study participants $\left(R^{2}=0.19\right.$; adjusted $R^{2}=0.17$; and $\left.F_{7,310}=10.44\right)$.

\begin{tabular}{llc}
\hline Variable & Statistics & \\
& Standardized beta coefficient & $P$ value \\
\hline Participant age & -.03 & .51 \\
Participant income (ref $\left.{ }^{\mathrm{a}} \leq \mathrm{Can} \$ 74,999\right)$ & -.08 & .17 \\
Mock profile owner gender (ref female) & -.10 & .05 \\
Health discipline (ref physician) & .65 & .21 \\
Ambiguous workday comment (ref evident frustration) & .39 & $<.001$ \\
Online recruitment (ref in person) & -.02 & .68 \\
Scenario view time (in seconds) & -.08 & .12 \\
Credibility rating & $-\mathrm{b}$ & - \\
\hline
\end{tabular}

${ }^{\mathrm{a}}$ Ref: referent.

${ }^{\mathrm{b}}$ Variable not included in the model in Step 1.

Table 4. Step 2 of the sequential regression examining credibility as a mediator in the relationship between workday comment type and willingness to become a patient of a physician or client of a veterinarian for 318 study participants $\left(R^{2}=0.57\right.$; adjusted $R^{2}=0.56$; change in $R^{2}=0.38$; and $\left.F_{1,309}=267.48\right)$.

\begin{tabular}{llc}
\hline Variable & Statistics & \\
& Standardized beta coefficient & $P$ value \\
\hline Participant age & -.02 & .70 \\
Participant income (ref $\left.{ }^{\mathrm{a}} \leq \mathrm{Can} \$ 74,999\right)$ & -.05 & .18 \\
Mock profile owner gender (ref female) & -.09 & .02 \\
Health discipline (ref physician) & .06 & .11 \\
Ambiguous workday comment (ref evident frustration) & .10 & .03 \\
Online recruitment (ref in person) & .06 & .10 \\
Scenario view time (in seconds) & -.06 & .12 \\
Credibility rating & .69 & $<.001$ \\
\hline
\end{tabular}

${ }^{\mathrm{a}}$ Ref: referent.

\section{Discussion}

\section{Principal Findings}

Facebook functions as a space to share information and access social support [29,30], including sharing workday frustrations [31]. Health professionals, regulators, and educators aim to better understand health professionals' personal use of social media and networking sites, especially Facebook, given its ubiquity in the personal lives of the general public and of health professionals [5-11]. This field study provides some of the first evidence that the blurring between private and professional lives that is inherent on health professionals' personal Facebook profiles warrants the attention of health professional communities. Participants independently noticed a subtle workday frustration comment on a mock health professional's personal Facebook account and perceived that individual as less credible than a mock health professional with an ambiguous workday comment. Participants also indicated less willingness to engage professionally with the profile owners who posted evident versus ambiguous frustration comments.
We found a small, though not statistically significant, difference between participant credibility ratings of physicians and veterinarians. Given the different health contexts for physicians and veterinarians, the findings of this study suggest that the public has expectations of online professionalism that warrant further exploration across a range of health professions to broaden our understanding of credibility evaluations in relation to and beyond those studied here.

\section{Comparison With Previous Work}

Our results seem consistent with a conventional view of professionalism and suggest that current cautions around health professionals' personal use of Facebook are not unreasonable [32]. Yet, mock profile owners in our study were rated somewhat less harshly (ie, still rated above the midpoint of the professionalism scale at 57 out of 100) than those in a similar study [33]; however, study design features may account for this difference. Jain et al had employees of a US university rate appropriateness (their measure of professionalism) of workday comments about patients made by medical students on a Likert 
scale (from 1-very inappropriate to 5-very appropriate); the average score was 1.88 [33]. Participants in that study were informed that the content was publicly available and searchable on Facebook and were asked to rate behaviors that were circled in red. In addition, workplace comments were combined for analysis, blending milder and more severe comments, all of which may have contributed to harsher ratings [33]. In contrast, we aimed to control socially desirable responses by having participants review the profile for as long as they wished, leaving them to independently notice both the workday comment and that the individual was a health professional.

In another study, Clyde et al suggest that clients may be motivated to search for health professionals online to supplement information available on a workplace website [34]. They found that Facebook profiles belonging to mock physicians with healthy personal information (eg, reading and hiking) were perceived as significantly more professional than profiles that limited content solely to information about mock physicians' education and current practice. Clyde et al interpreted this to mean that access to personal information allowed participants to better judge physicians' professionalism attributes [34]. Their finding was unexpected [34], perhaps because conventionally, personal self-disclosure (even of a positive nature) by physicians is thought to lower professional boundaries and is largely perceived as having a detrimental effect on the health relationship [35,36]. However, as with this study, their findings highlight the importance that health professionals' personal disclosures online may have with patients.

\section{Strengths and Limitations}

Key strengths of this field study were the random presentation of mock profiles and the realistic context of the survey design, which parallels the way a health professional's Facebook information may be discovered online. The use of indirect questions to assess judgments of health professionals [37] and anonymity in survey completion [38] likely limited social desirability responses. The proportion of females $(62 \%)$ to males in this study was more representative than in traditional survey methods, where women often comprise $71 \%$ to $77 \%$ of the participants [39], and the average age of participants in this study (40 years) is similar to the average age of a social media user (38 years) [29].

Nevertheless, choosing a health care provider involves more factors than were measured in this study, such as location and word-of-mouth referrals. Facial gestures and physical traits also influence impressions [40], as do characteristics of the trustor [41], comments posted by friends, and personality traits of the trustee $[42,43]$, which were not examined here.

\section{Implications for Practice and Social Media Guidelines}

In a recent exploration of dentists' and patients' attitudes toward social media use, $36 \%$ of patients reported searching for their dentist or doctor on social media. Other findings highlighted patients' desire for more information about their health professionals (eg, by reading online reviews and qualifications) [44]. These findings underscore the near impossibility for health professionals in defending strict boundaries between their private and professional selves online but, rather, suggest the value of further research to better understand the impacts of unintentional patient communication of this type.

We conclude that health professionals, especially early-career professionals who have yet to build their professional reputation, should be mindful of their credibility with the public when using Facebook in their private lives. Adhering to social media guidelines that take a traditional or conventional view of professionalism is a reasonable first step, especially around workday comments. Although confidentiality breeches are more serious and have been a focus of attention for regulators and educators, they are rare $[12,18]$, whereas, workday comments are common on Facebook [12,18-20,22]. We acknowledge that such a recommendation is associated with significant burden for health professionals, who have a right to access social support on Facebook when acting as private citizens. However, these rights need to be balanced with their professional obligation to maintain positive health relationships [13].

\section{Conclusions}

Although a fuller understanding of e-professionalism is ongoing in this field, given the profound effect of digital technologies on society, social media guidelines should incorporate early evidence to prevent credibility damage because (1) trust, once broken, is difficult to rebuild [45]; (2) Facebook is seemingly rooted in society, with 1 in 5 Americans using social media for health care decisions ( $94 \%$ of whom reported Facebook as their trusted source) [46]; and (3) recent evidence suggests that health professionals do indeed friend patients [44]. This study underscores that the blurring of professional and personal lives on social media is important to understand and manage. Better elucidating patients' differing perspectives of e-professionalism around various workday comments and identifying contextual influences, such as views about whether Facebook is private or public, will better define expectations of e-professionalism, which may in turn alleviate some of the concerns and reticence among health professionals to participate in social media.

Furthermore, an untapped area of health communication research includes the evaluation of health professionals use of social media skills in the public domain, that is, when, as private citizens, they participate in broader public online discussion about health matters within their professional domain (eg, posting comments in the comments section in news articles about vaccination).

\section{Acknowledgments}

CW's stipend was funded by the Canadian Institutes of Health Research under grant number 599547. 


\section{Conflicts of Interest}

None declared.

\section{References}

1. Cruess SR, Johnston S, Cruess RL. "Profession": a working definition for medical educators. Teach Learn Med 2004;16(1):74-76. [doi: 10.1207/s15328015tlm1601 15] [Medline: 14987179$]$

2. McCroskey JC, Teven JJ. Goodwill: a reexamination of the construct and its measurement. Commun Monogr 2009 Jun 02;66(1):90-103. [doi: 10.1080/03637759909376464]

3. Shay LA, Dumenci L, Siminoff LA, Flocke SA, Lafata JE. Factors associated with patient reports of positive physician relational communication. Patient Educ Couns 2012 Oct;89(1):96-101 [FREE Full text] [doi: 10.1016/j.pec.2012.04.003] [Medline: 22554386]

4. Fox S. Pew Research Center. 2011 Feb 01. Health topics URL: http://pewinternet.org/Reports/2011/HealthTopics.aspx [accessed 2018-08-23] [WebCite Cache ID 71tHGIIbn]

5. Christofides E, Muise A, Desmarais S. Hey Mom, What's on Your Facebook? Comparing Facebook disclosure and privacy in adolescents and adults. Soc Psychol Pers Sci 2011 May 17;3(1):48-54. [doi: 10.1177/1948550611408619]

6. Christofides E, Muise A, Desmarais S. Information disclosure and control on Facebook: are they two sides of the same coin or two different processes? Cyberpsychol Behav 2009 Jun;12(3):341-345. [doi: 10.1089/cpb.2008.0226] [Medline: $\underline{19250020]}$

7. MacDonald J, Sohn S, Ellis P. Privacy, professionalism and Facebook: a dilemma for young doctors. Med Educ 2010 Aug;44(8):805-813. [doi: 10.1111/j.1365-2923.2010.03720.x] [Medline: 20633220]

8. Bosslet GT, Torke AM, Hickman SE, Terry CL, Helft PR. The patient-doctor relationship and online social networks: results of a national survey. J Gen Intern Med 2011 Oct;26(10):1168-1174 [FREE Full text] [doi: 10.1007/s11606-011-1761-2] [Medline: 21706268]

9. Coe JB, Weijs CA, Muise A, Christofides E, Desmarais S. Understanding veterinary students' use of and attitudes toward the social networking site, Facebook, to assist in developing curricula to address online professionalism. J Vet Med Educ 2012;39(3):297-303. [doi: 10.3138/jvme.0212-016R] [Medline: 22951465]

10. Ross S, Lai K, Walton JM, Kirwan P, White JS. "I have the right to a private life": medical students' views about professionalism in a digital world. Med Teach 2013 Oct;35(10):826-831. [doi: 10.3109/0142159X.2013.802301] [Medline: $\underline{23826730}$

11. Weijs CA, Coe JB, Muise A, Christofides E, Desmarais S. Reputation management on facebook: awareness is key to protecting yourself, your practice, and the veterinary profession. J Am Anim Hosp Assoc 2014;50(4):227-236. [doi: 10.5326/JAAHA-MS-6069] [Medline: 24855091]

12. Chretien KC, Tuck MG. Online professionalism: a synthetic review. Int Rev Psychiatry 2015 Apr;27(2):106-117. [doi: 10.3109/09540261.2015.1004305] [Medline: 25804627]

13. Chretien KC, Kind T. Climbing social media in medicine's hierarchy of needs. Acad Med 2014 Oct;89(10):1318-1320 [FREE Full text] [doi: 10.1097/ACM.0000000000000430] [Medline: 25076202]

14. Cain J, Romanelli F. E-professionalism: a new paradigm for a digital age. Current Pharm Teach Learn 2009 Dec;1(2):66-70. [doi: $10.1016 /$ j.cptl.2009.10.001]

15. Conaboy C. The Boston Globe. 2011 Apr 20. For doctors, social media a tricky case URL: http://www.webcitation.org/ 71sR7xWAq [accessed 2018-08-22] [WebCite Cache ID 71sR7xWAq]

16. Griffith R, Tengnah C. District nurses' use of social networking sites: caution required. Br J Community Nurs 2011 Sep;16(9):455-457. [doi: 10.12968/bjen.2011.16.9.455] [Medline: 22067956]

17. Flickinger TE, O'Hagan T, Chisolm MS. Developing a curriculum to promote professionalism for medical students using social media: pilot of a workshop and blog-based intervention. JMIR Med Educ 2015 Dec 01;1(2):e17 [FREE Full text] [doi: 10.2196/mededu.4886] [Medline: 27731846]

18. Black EW, Thompson LA, Duff WP, Dawson K, Saliba H, Black NM. Revisiting social network utilization by physicians-in-training. J Grad Med Educ 2010 Jun;2(2):289-293 [FREE Full text] [doi: 10.4300/JGME-D-10-00011.1] [Medline: 21975635]

19. Borgstrom E, Cohn S, Barclay S. Medical professionalism: conflicting values for tomorrow's doctors. J Gen Intern Med 2010 Dec;25(12):1330-1336 [FREE Full text] [doi: 10.1007/s11606-010-1485-8] [Medline: 20740324]

20. Coe JB, Weijs CA, Muise A, Christofides E, Desmarais S. Teaching veterinary professionalism in the Face(book) of change. J Vet Med Educ 2011;38(4):353-359. [doi: 10.3138/jvme.38.4.353] [Medline: 22130411]

21. Weijs CA, Coe JB, Christofides E, Muise A, Desmarais S. Facebook use among early-career veterinarians in Ontario, Canada (March to May 2010). J Am Vet Med Assoc 2013 Apr 15;242(8):1083-1090. [doi: 10.2460/javma.242.8.1083] [Medline: 23547671]

22. Thompson LA, Dawson K, Ferdig R, Black EW, Boyer J, Coutts J, et al. The intersection of online social networking with medical professionalism. J Gen Intern Med 2008 Jul;23(7):954-957 [FREE Full text] [doi: 10.1007/s11606-008-0538-8] [Medline: 18612723] 
23. Edwards AL. The Social Desirability Variable in Personality Assessment and Research. Worcester, Massachusetts, United States: American Psychological Association; 1958:610-611.

24. Heise D. The Semantic differential attitude research. In: Summers GF, editor. Attitude Measurement. Oregon: Kershaw Publishing Co Ltd; 1970:235-253.

25. Gerich J. Visual analogue scales for mode-independent measurement in self-administered questionnaires. Behav Res Methods 2007 Nov;39(4):985-992. [Medline: 18183916]

26. Tabachnick BG, Fidell LS. Using Multivariate Statistics. 6th edition. Boston, MA: Pearson; 2013:- .

27. Soper D. Daniel Soper. 2015. Effect Size Calculator for Hierarchical Multiple Regression URL: https://www.danielsoper.com/ statcalc/default.aspx [accessed 2018-08-23] [WebCite Cache ID 71tEyi9Uk]

28. Soper D. Daniel Soper. 2015. f-square effect size confidence interval calculator URL: https://www.danielsoper.com/statcalc/ calculator.aspx?id=75 [accessed 2018-08-23] [WebCite Cache ID 71tFCOR9H]

29. Hampton K, Goulet L, Rainie L, Purcell K. Pew Research Center. 2011 Jun 16. Social networking sites and our lives URL: http://www.pewinternet.org/2011/06/16/social-networking-sites-and-our-lives/ [accessed 2018-08-23] [WebCite Cache ID 71tGULztR]

30. Ellison NB, Vitak J, Gray R, Lampe C. Cultivating social resources on social network sites: Facebook relationship maintenance behaviors and their role in social capital processes. J Comput Mediat Commun 2014 Jul 01;19(4):855-870. [doi: 10.1111/jcc4.12078]

31. Farnan JM, Paro JA, Higa J, Edelson J, Arora VM. The YouTube generation: implications for medical professionalism. Perspect Biol Med 2008;51(4):517-524. [doi: 10.1353/pbm.0.0048] [Medline: 18997354]

32. Mayer MA, Leis A, Mayer A, Rodriguez-Gonzalez A. How medical doctors and students should use Social Media: a review of the main guidelines for proposing practical recommendations. Stud Health Technol Inform 2012;180:853-857. [Medline: 22874313]

33. Jain A, Petty EM, Jaber RM, Tackett S, Purkiss J, Fitzgerald J, et al. What is appropriate to post on social media? Ratings from students, faculty members and the public. Med Educ 2014 Feb;48(2):157-169 [FREE Full text] [doi: 10.1111/medu.12282] [Medline: 24528398]

34. Clyde JW, Domenech Rodríguez MM, Geiser C. Medical professionalism: an experimental look at physicians' Facebook profiles. Med Educ Online 2014;19:23149 [FREE Full text] [doi: 10.3402/meo.v19.23149] [Medline: 24947922]

35. McDaniel SH, Beckman HB, Morse DS, Silberman J, Seaburn DB, Epstein RM. Physician self-disclosure in primary care visits: enough about you, what about me? Arch Intern Med 2007 Jun 25;167(12):1321-1326. [doi:

10.1001/archinte.167.12.1321] [Medline: 17592107]

36. Beach MC, Roter D, Rubin H, Frankel R, Levinson W, Ford DE. Is physician self-disclosure related to patient evaluation of office visits? J Gen Intern Med 2004 Sep;19(9):905-910 [FREE Full text] [doi: 10.1111/j.1525-1497.2004.40040.x] [Medline: $\underline{15333053]}$

37. Lount RB, Pettit NC. The social context of trust: the role of status. Organ Behav Hum Decis Process 2012 Jan;117(1):15-23. [doi: 10.1016/j.obhdp.2011.07.005]

38. Denissen JJ, Neumann L, van Zalk M. How the internet is changing the implementation of traditional research methods, people's daily lives, and the way in which developmental scientists conduct research. Int J Behav Dev 2010 Oct 27;34(6):564-575. [doi: 10.1177/0165025410383746]

39. Gosling SD, Vazire S, Srivastava S, John OP. Should we trust web-based studies? A comparative analysis of six preconceptions about internet questionnaires. Am Psychol 2004 Mar;59(2):93-104. [doi: 10.1037/0003-066X.59.2.93] [Medline: 14992636]

40. Krumhuber E, Manstead AS, Cosker D, Marshall D, Rosin PL, Kappas A. Facial dynamics as indicators of trustworthiness and cooperative behavior. Emotion 2007 Nov;7(4):730-735. [doi: 10.1037/1528-3542.7.4.730] [Medline: 18039040]

41. Viggiano MP, Marzi T. Chapter 8: Context and social effects on face recognition. In: Balcetis E, Lassiter DG, editors. The Social Psychology of Visual Perception. New York, NY: Psychology Press; 2010:171-200.

42. Tong ST, van der Heide B, Langwell L, Walther JB. Too much of a good thing? The relationship between number of friends and interpersonal impressions on facebook. J Comput Mediat Commun 2008;13(3):531-549. [doi: 10.1111/j.1083-6101.2008.00409.x]

43. Utz S, Tanis M, Vermeulen I. It is all about being popular: the effects of need for popularity on social network site use. Cyberpsychol Behav Soc Netw 2012 Jan;15(1):37-42. [doi: 10.1089/cyber.2010.0651] [Medline: 21988765]

44. Parmar N, Dong L, Eisingerich AB. Connecting with your dentist on Facebook: patients' and dentists' attitudes towards social media usage in dentistry. J Med Internet Res 2018 Jun 29;20(6):e10109 [FREE Full text] [doi: 10.2196/10109] [Medline: 29959108]

45. Rempel JK, Holmes JG, Zanna MP. Trust in close relationships. J Personal Soc Psychol 1985;49(1):95-112. [doi: 10.1037/0022-3514.49.1.95]

46. National Research Corporation. 2011. 1 in 5 Americans Use Social Media for Health Care Information URL: http://hcmg. nationalresearch.com/public/News.aspx?ID=9 [accessed 2018-08-21] [WebCite Cache ID 71tH2VgLU] 


\section{Abbreviations}

ANOVA: analysis of variance

Edited by G Eysenbach; submitted 23.08.18; peer-reviewed by J Cain, B Bie, C Lammert, S Manca, A Kulanthaivel; comments to author 23.01.19; accepted 17.02.19; published 18.04.19

Please cite as:

Weijs C, Coe J, Desmarais S, Majowicz S, Jones-Bitton A

Effects of Mock Facebook Workday Comments on Public Perception of Professional Credibility: A Field Study in Canada

J Med Internet Res 2019;21(4):e12024

URL: http://www.jmir.org/2019/4/e12024/

doi: $10.2196 / 12024$

PMID: 30998223

(C) Cynthia Weijs, Jason Coe, Serge Desmarais, Shannon Majowicz, Andria Jones-Bitton. Originally published in the Journal of Medical Internet Research (http://www.jmir.org), 18.04.2019. This is an open-access article distributed under the terms of the Creative Commons Attribution License (https://creativecommons.org/licenses/by/4.0/), which permits unrestricted use, distribution, and reproduction in any medium, provided the original work, first published in the Journal of Medical Internet Research, is properly cited. The complete bibliographic information, a link to the original publication on http://www.jmir.org/, as well as this copyright and license information must be included. 